\title{
Reformulando los conceptos asimétricos: la simetría de la asimetría
}

\author{
Asymmetrical Concepts Reformulating: the asymmetry's symmetry
}

\author{
Ana Isabel González Manso \\ anabel.gonzalez.manso@gmail.com \\ Investigadora \\ UPV/EHU \\ Paseo Pintor Rosales 80, $6^{\circ}$ \\ 28008 - Madrid \\ España
}

\begin{abstract}
Resumen
Los conceptos asimétricos definidos por Reinhart Koselleck tienen una gran utilidad como herramienta analítica dado que están inmersos en la problemática de la identidad del "nosotros" frente al "ellos", al tiempo que reflejan las estructuras de dominio contenidas en el lenguaje y en los conceptos. Este trabajo analiza en particular las relaciones simétricas y asimétricas de los conceptos opuestos, para proponer que un solo concepto puede jugar el papel de un par de contra-conceptos dadas las diferentes cargas valorativas con que le dotan dos grupos en lucha. Se ejemplifica esta propuesta a través de la utilización de "nobleza" como concepto asimétrico por parte de dos tendencias del liberalismo en la primera mitad del siglo XIX en España.
\end{abstract}

\section{Palabras-clave}

142

Reinhart Koselleck; Identidad; Representación.

\section{Abstract}

Asymmetrical Concepts, defined by Reinhart Koselleck, have a strong utility as analytical tools: in fact they are deeply involved not only in the identity questions regarding "Us" against "Others" but also in the supremacy structures contained in the language and concepts. This work analyzes in detail the symmetrical and asymmetrical relationships of the opposite concepts in order to propose that one concept may play the role of a couple of counter-concepts. This occurs owing to the fact that two fighting groups give different evaluations of that concept. This theoretic proposal is exemplified by the use of the "nobility" concept as an asymmetrical concept by two liberal tendencies in Spain in the first half of nineteen Century.

\section{Keywords}

Reinhart Koselleck; Identity; Representation.

Recibido el: 19/3/2015

Aceptado el: 30/11/2015 
Reinhart Koselleck definió hace ya más de treinta años los conceptos asimétricos (a partir de ahora CA) analizando los casos de Helenos/Bárbaros, Cristianos/Paganos, Hombre/no Hombre (superhombre/ infrahombre) (KOSELLECK 1979). ${ }^{1}$ Desde este trabajo, diferentes autores han utilizado los CA como herramienta analítica en los estudios sociales dado que los CA están inmersos en la problemática de la identidad del "Nosotros" frente al "Ellos" al tiempo que reflejan las estructuras de dominio contenidas en el lenguaje y en los conceptos (FERES Jr. 2006; JUNGE; POSTOUTENKO 2011; STROHSCHNEIDER 2012). Dado que los CA entran además en el campo de las prácticas discursivas, ha sido frecuente acercarse a ellos desde la óptica de las principales metodologías que aúnan el estudio de la identidad y del discurso, es decir el "Análisis de la Conversación" (SCHEGLOFF 1997), el "Análisis Crítico del Discurso" o la "Teoría del Posicionamiento" (HARRE; van LANGENHOVE 1999). Estas metodologías buscan comprender cómo las fuerzas históricas y socioculturales afectan al discurso dominante y cómo la posición de los hablantes es construida y elige los elementos con los que construir su identidad con respecto a los otros y con respecto al discurso dominante (De FINA; SCHIFFRIN; BAMBERG 2006, p. 7). En el fondo son metodologías que defienden el constructivismo social pero buscando un acercamiento que no anule la esencia individual, que no deje fuera la "tensión irreductible que define la acción humana" (WERTSCH 1997, p. 6-7). Sin invalidar por supuesto, y compartiendo gran parte del interés por este tipo de enfoques, en el análisis que propongo en las páginas siguientes la metodología utilizada está más cerca de la empleada por Koselleck, es decir, una aproximación conceptual que evidencie la estructura semántica en la que radica la asimetría de los CA, por considerar que capta mejor todas las diferentes situaciones en acto.

Las representaciones sociales del pasado que sustentan la identidad grupal, desde una óptica constructivista, implican la reconstrucción del pasado como base de la memoria social. Mediante el anclaje y la objetivación, presente y futuro se recombinan en el pasado dando continuidad e identidad. ${ }^{2}$ En mi opinión estos fenómenos de anclaje y objetivación serían consecuencia de la abstracción (y así pues de la mayor complejidad) de los conceptos, observable desde mediados del siglo XVIII: los seres humanos necesitan acercar los conceptos mediante imágenes concretas para facilitar su comprensión. Estas imágenes no solo tienen un significado explícito, sino que también acarrean otros ocultos a través de los sentimientos que son capaces de despertar en cada individuo perteneciente a una comunidad (BARTLETT 1932, p. 215-

\footnotetext{
${ }^{1}$ Los conceptos contrarios o contra-conceptos, implican una conciencia y una valoración del Nosotros y del Ellos. Para que el grupo Nosotros se convierta en una unidad de acción, y ésta sea eficaz, necesita definirse de acuerdo a conceptos que lo diferencien de los demás grupos. Las unidades históricas de acción adaptan conceptos generales a la singularidad para determinarse, excluyendo a los demás grupos de poder adherirse a esos mismos conceptos y atribuyéndoles conceptos contrarios. Así surgen para este autor los conceptos contrarios asimétricos (KOSELLECK 1993, p. 205-206).

${ }^{2}$ Anclar es clasificar y nombrar algo, lo cual implica darle un valor positivo o negativo, confinarlo en un conjunto de comportamientos y reglas. Objetivar es descubrir la cualidad icónica de una idea o un ser impreciso, reproducir un concepto en una imagen. Las imágenes relacionadas pasan a formar un núcleo figurativo que reproduce visiblemente un complejo de ideas, lo que facilita que la gente hable de ello cada vez más; esto lleva a que este paradigma figurativo cobre una independencia propia, quedando suelto en la sociedad que lo acepta como una realidad, convencional pero no por ello menos real. "La imagen se puede llegar a asimilar totalmente y lo percibido remplaza a lo concebido". (ROSA; BELLELLI; BAKHURST 2000, p. 74)
} 
226). El recuerdo voluntario (o involuntario) de memorias colectivas, tiene un propósito moral, cumple la función de mover a la acción en una dirección particular (ROSA; BELLELLI; BAKHURST 2000, p. 47). La memoria colectiva está sujeta a una continua co-construcción entre los miembros del grupo, no es un producto acabado sino un terreno de disputa entre diferentes visiones del pasado, del presente y del futuro colectivo (TODOROV 2008, p. 93). Para Teun A. van Dijk la identidad de un grupo se asocia con ideología, entendida ésta como las "creencias fundamentales que forman la base de las representaciones sociales de un grupo. Se representan en la memoria social como "esquemas del grupo" que definen su identidad" (van DIJK 2003, p. 77). La ideología nos llevaría "a construir una trama narrativa (ludus) en la que el pasado y el presente se vinculan para proyectar un futuro imaginado (mythos) a partir de los valores preferidos que, al mismo tiempo, convierten a unos hechos del pasado en más memorables que otros" (ROSA; BLANCO; TRAVIESO; HUERTAS 2000, p. 354). Los grupos, al igual que los individuos, "utilizan los recuerdos con fines identitarios, lo que hace que en ocasiones su memoria se vea distorsionada para mantener una buena imagen de sí mismos" (ROSA; BELLELLI; BAKHURST 2000, p. 70). Según Roy F. Baumeister y Stephen Hastings las formas de distorsión son el auto engaño (tendencia a la omisión selectiva de acontecimientos desagradables, invención de acontecimientos pasados), la manipulación de asociaciones entre acontecimientos (se exagera una de las causas de los acontecimientos y se minusvaloran otras), la proyección de la propia culpa sobre el enemigo o la atribución de la responsabilidad al marco contextual (BAUMEISTER; HASTINGS 1997). Todas estas técnicas serán utilizadas retóricamente en los discursos y quedaran condensadas, apresadas en los CA tal y como veremos a continuación.

El estudio de los CA, como podemos observar, es enormemente complejo porque implica cuestiones de identidad, de representaciones sociales del pasado y de ideologías que se pueden abordar desde diferentes metodologías. En el presente trabajo pretendo analizar en primer lugar, partiendo del estudio realizado por Koselleck, las diferentes problemáticas que rodean la definición y el posible uso de los CA. En segundo lugar focalizaré este abordaje teórico con su puesta en práctica en el uso de un solo concepto, el de "nobleza" como concepto asimétrico, por parte de dos tendencias del liberalismo en la primera mitad del siglo XIX en España.

\section{Qué se puede entender por CA y cuál sería su utilidad}

Koselleck, en su trabajo sobre los CA de 1979, centró su interés solo en parejas de conceptos contrarios con pretensión universal (Helenos/ Bárbaros, Cristianos/ Paganos y Hombre/ no hombre) para poder analizar la estructura semántica de la asimetría que contenían (KOSELLECK 1993, p. 209). Estas parejas de conceptos se pueden separar del contexto en el que surgieron y trasplantarse históricamente, cambiando su cualidad y su acción en el curso del tiempo (KOSELLECK 1993, p. 209-210). Pero Koselleck, poniendo de relieve el papel de los CA en la autodefinición de la identidad, dejó sin apenas consideración 
la posición del grupo "Ellos", siendo solo vista a través de la mirada del grupo "Nosotros". En estudios posteriores este autor fue complejizando el contenido de los CA, apareciendo así los conceptos sucesivos, correlativos y complementarios (KOSELLECK 2012, p. 107), teniendo más en cuenta aspectos del discurso hablado y escrito y su instrumentación política (KOSELLECK 2012, p. 190) y abogando finalmente por la necesidad de realzar la mirada del grupo "Ellos". De hecho, este aspecto es el que ha centrado la atención de los autores que se han interesado en la aplicación de los CA a los estudios sociales (FERES Jr. 2006, p. 266; POSTOUTENKO 2011, p. 82-83). Otro de los aspectos que también ha suscitado debate es la importancia de la relación asimétrica o simétrica entre los conceptos opuestos (JUNGE 2011, p. 35-36 y 42), aspecto que vamos a analizar a continuación.

\section{A. Relación asimétrica}

Koselleck definió la asimetría como "aquellas coordinaciones desigualmente contrarias y que solo se aplican unilateralmente" (KOSELLECK 1993, p. 205). Pero no mencionó el porqué de su aplicación unilateral y ésta, en mi opinión, tendría dos diferentes causas: porque a quién se le aplica un concepto, que en teoría lo define, no se reconoce (o no se quiere reconocer) en esa calificación a pesar de entender el lenguaje del forjador de la asimetría o porque no puede reconocerse pues supone el manejo de conceptos que no pertenecen a su mundo conceptual. Estas dos situaciones implican una gran diferencia en el uso asimétrico de los contra-conceptos tal y como desarrollaremos ampliamente más adelante. Haremos aquí dos breves observaciones: en el primer caso la asimetría se produciría por la imposibilidad por parte del grupo "Ellos" de responder a la calificación que le atribuye el grupo "Nosotros"; este caso lo contemplamos en el apartado Ab. En el segundo caso, que analizamos en el apartado Aa, y que es el que estudia Koselleck en sus ejemplos de Helenos/Bárbaros o Cristianos/ Paganos, la asimetría no es voluntaria, se produce obligatoriamente desde el mundo conceptual del grupo "Nosotros". En realidad no sabemos lo que ocurre desde la óptica del grupo "Ellos": es posible pensar que a su vez el grupo "Ellos" utilice otros contra-conceptos pertenecientes a su mundo conceptual para autodefinirse y definir al otro grupo que en ese caso pasa a ser "Ellos".

\section{Aa. Ambos grupos no comparten el mismo universo conceptual}

Los CA servirían solo para definir el universo conceptual del que los utiliza (grupo "Nosotros") a través de las características que atribuye al grupo "Ellos"; por su impostación da lugar siempre a contra-conceptos en relación asimétrica pues solo son utilizados por una de las partes, mientras que la otra parte no puede reconocerse en ellos, y así pues no tiene sentido que los utilice, pues no pertenecen a su universo conceptual. Una etnia es consciente de su propia identidad; una categoría étnica no tiene autoconciencia de su propia identidad pues es designada como grupo desde fuera, sin que sus miembros se reconozcan como tales (SMITH 1991, p. 20-21).

El grupo "Nosotros", que está buscando autodefinirse, asocia al grupo "Ellos" características negativas mientras que a su propio grupo las características 
positivas opuestas. En algunos casos, como sucedió durante la Ilustración con el concepto Bárbaros (baste pensar en el buen salvaje rousseauniano), puede darse un proceso de autocrítica dentro del grupo "Nosotros" que conllevará una revaloración positiva del grupo "Ellos". Pero en realidad esta práctica responde al mismo mecanismo aplicado cuando se atribuyen características negativas al grupo "Ellos": deseo de definición del grupo "Nosotros" sin un deseo de conocer al grupo "Ellos", grupo que no tiene, por otra parte, conciencia de ser homogéneo (ni es capaz de articular un discurso homogéneo frente al grupo "Nosotros") y que en la práctica suele estar constituido por muchos grupos. La aparente homogeneidad del grupo "Ellos" viene del hecho de que solo se está considerando la mirada del grupo "Nosotros" hacia el exterior de su propio grupo. El grupo "Nosotros" sería homogéneo, el/los grupo(s) "Ellos" también, visto solo desde la posición del grupo "Nosotros"; visto desde la óptica del grupo(s) "Ellos", éstos no se consideran, ni lo son en la mayoría de los casos, un grupo homogéneo ni tampoco consideran al grupo "Nosotros" como un grupo homogéneo. La realidad del/los grupo(s) "Ellos" no interesa al grupo "Nosotros" por lo cual solo es considerado desde la óptica de la autodefinición del grupo "Nosotros". Los miembros del grupo "Nosotros", a través de la propia autodefinición, buscan una acción inmediata contra el grupo "Ellos". Por ello, el discurso realizado desde el grupo "Nosotros" va dirigido a sus propios miembros y no a los del grupo "Ellos". Este tipo de relación asimétrica queda perfectamente ejemplificada en situaciones de colonialismo o de imperialismo: el grupo colonizador o imperialista busca a través de su propia autodefinición, justificar su acción de sometimiento de la población colonizada.

Al estar considerando una situación de universos conceptuales diferentes por lo general, aunque no obligatoriamente, el grupo "Nosotros" y el/los grupo(s) "Ellos" ocuparían espacios físicos diferentes y habría un deseo de imposición del primero sobre el/los segundo(s). Mientras que la calificación negativa del grupo "Ellos" se limite a discursos dirigidos a los miembros del grupo "Nosotros", no debería provocar ninguna reacción identitaria en el/los grupo/s "Ellos". Desde el momento en el que ese discurso se traduzca en una reacción física de ataque, de sometimiento, el grupo "Nosotros" podrá ser visto como enemigo por parte del/los grupo(s) "Ellos". Esta situación ¿provocaría un proceso de unificación-identificación en el seno del grupo "Ellos"? Solo en parte y dirigida a una acción inmediata defensiva que no implica un fenómeno identitario de la misma naturaleza que el originado en el grupo "Nosotros". Analizaremos esta situación en el apartado Ba.

Ab. Ambos grupos comparten el mismo universo conceptual, pero un grupo ostenta todo el poder y no deja medios de expresión al/los grupos "Ellos" o la expresión de los mismos es minoritaria y así pues difícil de valorar

Si en el primer caso el grupo "Nosotros" define al grupo "Ellos" con vistas a poder dominarlo, en este caso la dominación física ya se ha consumado y lo que busca el grupo "Nosotros" es poder reforzar el control sobre el grupo "Ellos". En este proceso de dominación el grupo "Ellos" puede adquirir conciencia de su identidad comunitaria frente al grupo "Nosotros" en el caso 
de no poseerla o infravalorarla. El ejemplo extremo considerado por Koselleck de Hombre/no hombre, en particular referido a la acción antisemita nazi, entraría dentro de esta casuística, aunque también se adapta a cualquier situación de dominio por parte de un grupo sobre otro/otros grupo(s) (ambos con conciencia de su propia identidad) en una sociedad concreta. Postoutenko califica esta asimetría de "Antagonística Fuerte"3 dentro de su clasificación de las asimetrías en un contexto explicativo más comunicativo que lingüístico o conceptual (POSTOUTENKO 2011, p. 92).

En este caso el discurso dentro del grupo "Nosotros" va dirigido no solo a sus propios miembros sino también a los miembros del grupo "Ellos". La asimetría nace del no reconocimiento por parte de uno de los grupos de las características que le atribuye el otro grupo y al mismo tiempo de la falta de capacidad (por falta de medios, represión...) para poder responderle en la misma medida. Este tipo de doble asimetría, en mi opinión, es más intensa y vivida más negativamente por una de las partes en conflicto frente al caso anterior: en el primer caso analizado, las atribuciones negativas realizadas por el grupo "Nosotros" no son entendidas ni pueden ser interiorizadas como negativas por parte del grupo "Ellos" al no hacer referencias a su mundo conceptual y así pues no tienen porque provocar una reacción de las mismas características. En cambio, en este caso, la atribución de conceptos negativos es perfectamente entendida por el grupo "Ellos", que se sentirá injustamente tratado, provocando una reacción, al menos en el interior del propio grupo (por no ser posible su expresión exterior al estar sometidos por el grupo "Nosotros"), conducente a reforzar su unidad e identidad. Nos encontramos, así pues, con que esta relación asimétrica de conceptos refuerza, simétricamente, las identidades de los grupos "Nosotros" e, involuntariamente, del/los grupos(s) "Ellos" mientras que en el caso anterior solo reforzaría, inicialmente, la identidad del grupo "Nosotros". La principal asimetría radicaría en la falta de expresión, al menos a través de los canales utilizados por el grupo "Nosotros", del grupo "Ellos" pero no implica la ausencia de expresión, al contrario, pues ésta se produce (pero solo en el interior del grupo "Ellos") y ayuda a reforzar la cohesión interna del grupo "Ellos".

En el primer caso analizado, la asimetría se basaría en que solo se refuerza la identidad de una de las partes en conflicto; en este segundo caso, los contra-conceptos provocarían una reacción simétrica de autodefinición y reforzamiento de la identidad en los dos grupos, descansando la asimetría en la falta de expresión, a través de los mismos canales de comunicación, de una de las partes. Son dos conceptos de asimetría totalmente diferentes.

\section{B. Relación simétrica}

¿Estaríamos pervirtiendo la esencia de las definiciones dadas por Koselleck sobre conceptos asimétricos si consideramos contra-conceptos en relación simétrica, o ayudaría a su aplicación como herramienta analítica en los estudios

\footnotetext{
${ }^{3}$ Strong Antagonistic Asymmetry.
} 
sociales? Sinceramente, consideramos que valorar la relación simétrica o asimétrica de los contra-conceptos, presentaría varias ventajas. La primera, y quizás la principal, el evitar la reproducción del discurso del grupo dominante. Si basamos la asimetría en la no identificación (motivada por cualquier causa: por pertenecer a mundos conceptuales diferentes o por no sentirse identificado en la valoración) de una las partes con los conceptos manejados por la otra parte, ¿por qué no analizar esta asimetría en un marco simétrico de igualdad de expresión y de creación de identidad de ambos grupos? Es decir valorar la simetría de la asimetría. El elemento de definición de la identidad destacado por Koselleck de los CA se mantendría pero ahora manifestado por ambos grupos y la posibilidad de análisis de su expresión permitiría superar las estructuras de dominio. Eso sí, entraríamos de lleno en la problemática de la lucha ideológica y del enfrentamiento político.

Ba. Los dos grupos no comparten el universo conceptual y cultural pero, a diferencia de la situación considerada en el apartado Aa, ambos grupos buscan autodefinirse a expensas del otro

Esta situación enlazaría con la planteada en el apartado Aa. Como consecuencia de la acción llevada a cabo por el grupo "Nosotros" contra el/los grupo(s) "Ellos", éstos, que hasta ese momento no habían sentido la necesidad de dar una respuesta a las invectivas discursivas por no sentirse identificados ni amenazados por ellas, reaccionan al ataque físico recibido, reforzando su propia identidad. La respuesta es con respecto a la acción física iniciada por el grupo "Nosotros", no con respecto al contenido valorativo de las calificaciones que les atribuye este grupo pues no se sienten definidos por ellas. En este caso el/los grupo(s) "Ellos" podrán usar otros conceptos en su autodefinición y en la calificación del otro grupo al que se opone(n), pero éstos estarán destinados principalmente a provocar una respuesta contra el grupo atacante. Estaríamos en la línea más genérica, más básica, de los contra-conceptos del tipo Amigos/ Enemigos que no en la línea más específica, ligada a valores culturales concretos, como pueden representar los conceptos Helenos/Bárbaros. En este supuesto, el grupo "Nosotros" puede seguir manejando conceptos ligados a sus valores culturales para definirse ( $y$ en la misma acción definir al grupo "Ellos"), mientras que el/los grupo(s) "Ellos" usarían conceptos que podríamos denominar "defensivos". Estos no harían tanto referencia a valores culturales propios del grupo en cuestión, como a valores que inviten a la acción directa defensiva. Podemos hablar dentro de esta simetría (ni "Nosotros" ni "Ellos" se sienten identificados con los conceptos aplicados por el otro grupo y ambos se autodefinen y definen al otro), de una cierta asimetría en el sentido de que el grupo "Nosotros" manejaría conceptos cargados de significados culturales mientras que el/los grupo(s) "Ellos" manejarían conceptos "defensivos", debido a la necesidad de inmediatez en la respuesta defensiva. Si el enfrentamiento entre el grupo "Nosotros" y el/lo(s) grupo(s) "Ellos" permaneciese en el tiempo en el campo discursivo sin pasar a la acción directa, entraríamos en la situación contemplada en el apartado Bb. 
Bb. Los dos grupos comparten el mismo universo conceptual y se produce una lucha discursiva en el campo ideológico para intentar convertirse en el grupo dominante

Esta situación es quizás la que se produce con mayor frecuencia en el mundo de las luchas políticas y, aunque no implica necesariamente acciones físicas de ataque, éstas pueden producirse por sentirse una de las partes en situación asimétrica con respecto al ejercicio del poder y/o a su capacidad de expresión. Haremos una breve mención a esta particularidad más adelante. De manera general la situación planteada en este apartado supone que, aunque no exista paridad de condiciones en cuanto a la expresión entre el grupo "Nosotros" y el/los grupo(s) "Ellos", sí contempla una posibilidad real de expresión de ambos grupos. Éstos se autodefinirán usando al otro grupo como referente negativo y a lo largo del enfrentamiento dialéctico se producirán cambios de posición y negociaciones. Este tipo de situación puede ser estudiada a través de una metodología de "Análisis de la Conversación", si se pone más el acento en la negociación de las posiciones de las partes, o a través de una metodología de "Análisis Crítico del Discurso", si se pone más el acento en el componente ideológico y las estructuras de dominio. De las diferentes situaciones contempladas, ésta quizás es la que presenta el carácter más contingente. Podría asimilarse con la "Asimetría Agonística Fuerte"4 definida por Postoutenko (POSTOUTENKO 2011, p. 95).

En este caso habría asimetría en cuanto a la no identificación con los conceptos atribuidos por el otro grupo (pero simetría en el sentido de que ambos grupos realizan la misma acción), simetría en la acción de usar conceptos culturales para autodefinirse ( $y$ definir al otro) y simetría en la capacidad de expresión de los mismos. Estaríamos ante un mayor grado de simetría en la utilización de la asimetría sin perder por ello la asimetría. Esta asimetría descansaría solo en la no identificación con el concepto ( $y$ el contenido que lo define) aplicado por un grupo con respecto al otro.

Este apartado es el más complejo y el que se presta a mayor número de variantes posibles. En primer lugar, tal y como mencionábamos al inicio de este apartado, existe la variante consistente en que una de las partes considere que existe asimetría, real o no, en la capacidad de expresión (en detrimento suyo) y así pues en sus posibilidades de ejercer un poder. La diferencia con el caso planteado en el apartado Ab es que en ese caso existía una asimetría objetiva en la capacidad de expresión mientras que en este caso la asimetría la crea la percepción de una de las partes. Esta percepción de la situación puede conducir a que esta parte en conflicto se sienta justificada a llevar el enfrentamiento discursivo al campo de la acción física ofensiva como único medio para poder expresarse.

En segundo lugar, y ya en el campo exclusivamente discursivo, podemos considerar la situación de que ambas partes en conflicto utilicen los mismos contra-conceptos para definirse y definir al otro. En este caso, ¿con qué situación de simetría/asimetría nos encontramos? Al pertenecer ambos grupos al mismo universo conceptual, aunque con posiciones ideológicas diferentes, pueden usar

\footnotetext{
${ }^{4}$ Strong Agonistic Asymmetry
} 
las mismas parejas de contra-conceptos para definirse ellos y definir al otro pero atribuyéndoles valores opuestos a los atribuidos por el otro grupo: por ejemplo y haciendo referencia a la España del siglo XIX, la pareja de contra-conceptos liberal/servil utilizados por los grupos liberales y los defensores de los principios del Antiguo Régimen. En este caso, ambos grupos utilizan estos dos conceptos para definirse y definir al otro: visto desde la perspectiva de los liberales, el concepto servil estará cargado de cualidades totalmente negativas mientras que visto desde la perspectiva servil será el concepto liberal el que detente todos los aspectos negativos. Podríamos pensar que en este caso se perdería la asimetría de no identificación con el concepto atribuido por el otro pues lo está utilizando para autodefinirse: pero no es así, porque en este caso, lo importante es la carga valorativa y reivindicativa con la que se dota a ese concepto. Al servil no le importa demasiado autodefinirse con el concepto de servil (este concepto arrastra significados lingüísticos negativos lo cual dificulta su uso en una autodefinición y a pesar de ello será reivindicada su utilización) desde el momento que lo dota de un contenido totalmente opuesto al que le atribuyen los liberales al hacer uso de él. Tal y como consideraba Koselleck en su estudio de 1979, no son tan importantes las palabras sobre las que descansan los conceptos asimétricos como la estructura asimétrica de argumentación. En este caso, esta estructura se basa en la diferente valoración atribuida por dos grupos, a una pareja de conceptos.

La siguiente variante que analizaré con más detalle por considerar que 150 presenta gran interés, es la de considerar si un solo concepto puede jugar el papel de un par de contra-conceptos por las diferentes cargas valorativas con la que le dotan dos grupos opuestos. Supone dar un paso más frente a lo considerado previamente: la estructura asimétrica de argumentación descansaría ahora en un solo concepto, con dos cargas valorativas opuestas atribuidas por dos grupos en lucha política. Existiría asimetría en cuanto a la no identificación con la valoración atribuida a ese concepto por el otro grupo, y simetría en cuanto a la utilización de un concepto para autodefinirse y definir al otro. Como veremos a continuación, existe una oposición neta en el contenido cultural definitorio y valorativo con el que se dota a ese concepto; como consecuencia, se hace innecesaria la utilización de dos conceptos opuestos. Con un solo concepto se consiguen los mismos resultados que con dos: autodefinirse, definir al otro, gestionar el enfrentamiento entre ambos grupos, reflejar los valores culturales de referencia de cada uno de ellos e incluso, en el ejemplo que analizaré, crear dos representaciones sociales del pasado con las que cada grupo enlazará. El uso de un concepto con fines asimétricos puede recordar el concepto de "nexus" definido por Michel Louis Rouquette aunque no tiene exactamente las mismas características pues el nexus no es una construcción destinada a comprender un contexto cultural; no se discute, como las representaciones sociales, es más bien una abstracción "proyectada". ${ }^{5}$ 
Para desarrollar el empleo de un solo concepto estudiaré un ejemplo concreto, la utilización del concepto "nobleza" por parte del mundo liberal en general y más específicamente por parte de dos tendencias del liberalismo, la moderada y la progresista, en la primera mitad del siglo XIX en España.

\section{Nobleza como concepto asimétrico}

Los inicios del siglo XIX en España supusieron, con la guerra de la Independencia contra Francia (1808-1814) y la aprobación de la Constitución liberal de Cádiz (1812), el reconocimiento de la soberanía nacional y el comienzo del fin, teórico, del Antiguo Régimen. La implantación de un régimen liberal no estuvo exento de ciertas dificultades pues, tras la proclamación de la Constitución gaditana y la salida del ejército francés de la península, en 1814 se produjo el retorno del rey tan deseado por los españoles, Fernando VII, retenido en Francia por Napoleón. Retorno que no se vio acompañado del mantenimiento de la Constitución liberal recién aprobada, sino que supuso un retorno al absolutismo durante un sexenio (1814-1820), junto con el exilio y encarcelamiento de numerosos políticos. Este periodo fue seguido de un interludio liberal de tres años (1820-1823), que permitió el restablecimiento de la Constitución y el intento de puesta en práctica de algunos de los principios liberales contenidos en la carta magna. El final del Trienio liberal se vio marcado por la entrada del ejército levantado por la Santa Alianza, los Cien Mil Hijos de San Luis, al frente del cual iba el conde de Angulema; esta intervención dio lugar a una nueva década absolutista del rey Fernando VII, que solo finalizó con su muerte (1833). Será a partir de ese momento cuando empezará a consolidarse, finalmente, el régimen liberal pero en un contexto político-cultural diferente del que vio en sus inicios.

A lo largo del periodo que estamos analizando, con el final del antiguo régimen y el inicio de un régimen liberal, el concepto "nobleza" jugó un papel importante en los debates políticos. Durante la redacción de la Constitución de Cádiz, y al querer acabar con los restos de feudalismo aún presentes en muchas instituciones, los políticos del momento se plantearon qué papel debían de jugar los nobles en el nuevo edificio político en construcción: ¿debían formar parte del nuevo parlamento (Cortes) dado que habían participado junto con el resto del pueblo en la defensa de España contra el invasor francés (1808-1814) o debían ser considerados reminiscencias del antiguo régimen y así pues elementos a eliminar o a quitarles protagonismo en el nuevo régimen político que se estaba gestando? De esta manera, el concepto "nobleza" pasó a convertirse en un elemento fundamental del debate político en los inicios del liberalismo (en paralelo con el concepto "pueblo") y a ser asociado con unas características en el pasado que le permitieran jugar un papel en el presente.

Podemos plantearnos si cuando los liberales, de cualquier tendencia, o los defensores del antiguo régimen mencionan el concepto nobleza, están 
refiriéndose a la nobleza de título o a una aristocracia que en muchos casos puede entenderse como élite intelectual o de protagonismo social. En el periodo que estamos considerando fue muy intenso el debate, no solo en España, del protagonismo que debían adquirir las clases medias, nueva "aristocracia" social. Las referencias a la nobleza medieval para sustentar el discurso político por parte de los intelectuales decimonónicos, haría pensar que noble implica solamente a aquellos individuos poseedores de un título nobiliario, en el pasado como en el presente. Pero el análisis de los discursos donde aparece esta defensa o crítica de los nobles, nos muestra que la situación es mucho más compleja, entremezclándose en este concepto diferentes significados: nobleza de título, élite intelectual, protagonista social, liderazgo político...No voy a analizar todos estos significados. Solo consideraré la valoración positiva o negativa del concepto nobleza según el actor político que lo utilice y la representación social del pasado con la que pretende enlazar, para mostrar cómo puede ser utilizado como concepto asimétrico.

¿Cómo consiguió el concepto "nobleza" ser un concepto clave en torno al cual rotaron gran parte de los debates parlamentarios y periodísticos y pasar a convertirse en un concepto asimétrico? La respuesta sería: a través de la relectura del papel de la nobleza en el pasado. Este papel, centrado específicamente en ciertos hechos históricos en los que los nobles se vieron implicados, realizará la función de objetivar, de reflejar a través de ciertas imágenes, las ideas políticas que definirán a cada tendencia liberal. Serán imágenes sacadas del "mercado 152 simbólico", definidas por Pierre Bourdieu (BOURDIEU 1994, p. 37-38), o de las tradiciones electivas definidas por Javier Fernández Sebastián (FERNÁNDEZ SEBASTIÁN 2014, p. 18-19). Para Serge Moscovici el consumidor de los productos simbólicos influirá sobre el propio proceso de producción mediante la atribución de un mayor o menor valor de verdad (o de uso) a estos productos (MOSCOVICI 1984, p. 29-30).

A continuación presentaré una serie de ejemplos que recogen el pensamiento liberal sobre este tema, y más en particular el de cada una de las tendencias liberales, a través de las reflexiones de algunos de los políticos-intelectuales del momento. Están obviamente muy ligadas al momento contextual del debate político, pero el contenido que se atribuirá en cada caso al concepto "nobleza" descansa en unas representaciones sociales de referencia para el grupo considerado. Estas reflexiones buscan, además de crear una autoidentidad común, provocar una acción concreta: son contingentes en cuanto a la acción buscada, pero estables en cuanto al mundo cultural al que se remiten. La asimetría contenida en la estructura de argumentación descansa en las diferentes relecturas de hechos del pasado. El mundo liberal, de hecho, releerá el pasado proyectando en él los deseos de reforma y cambio que deseaban para su presente y futuro: es decir, verán elementos de los nuevos conceptos políticos manejados en épocas remotas como la Edad Media. El pasado servirá para proyectar en él los deseos de construcción de la nueva sociedad: los políticos recrearán en el pasado las características de la nueva sociedad a construir, reflejando así pues esa relectura del tiempo remoto las diferencias entre las tendencias ideológicas. 
La mayoría de los intelectuales españoles hasta el Trienio liberal (1820-1823), destacaron que uno de los rasgos que diferenció a España del resto de Europa (Ilegando a crear un modelo historiográfico que ha perdurado hasta bien avanzado el siglo XX) fue el tipo de régimen feudal que hubo en el Medievo español y que explicaría la diferente situación y papel de la nobleza en el siglo XIX en España y en el resto de Europa. Esta diferenciación entre la nobleza española y la europea servirá a los políticos liberales para justificar el diferente camino seguido, frente a Francia en particular, en el establecimiento de un régimen liberal en la península. En este caso, el concepto "nobleza" y el pasado histórico con el que se le dota sirve como elemento en la autodefinición del movimiento liberal español frente al modelo francés o europeo en general, al tiempo que incita a la acción bajo varias perspectivas: ayudaría en la construcción del edificio liberal, marcando las características que deberían tener los nobles en la nueva sociedad ( $y$ estableciendo así diferencias con respecto al pensamiento de los defensores del antiguo régimen), en la oposición al intrusismo de ideas foráneas y alentando el prestigio de la nación española. Existirá asimetría en cuanto que esta autodefinición va realizada mirando hacia el interior de la sociedad española, no importa en realidad el pasado o el presente de la nobleza francesa o europea. Aunque nos movemos en un mismo marco conceptual, esta situación sería muy semejante, en esencia, a la analizada en el apartado Aa, aunque aquí manejando un solo concepto dotado de una valoración doble opuesta, y que se utiliza con vistas a la autodefinición del propio grupo sin interés por el conocimiento o la opinión del Otro (que en este caso puede que no responda a este ataque discursivo por no sentirse afectado directamente por el mismo).

Así podemos apreciar en este periodo que, para los liberales, los nobles españoles en la Edad Media no solo no se habrían manchado con un comportamiento reprensible de abusos sino que habrían actuado como intermediarios entre el rey y el pueblo, pero siempre del lado de este último. Intelectuales como Alberto Lista afirmarán: "Los privilegios feudales nunca fueron tan absurdos e injustos entre nosotros como en Francia: así nunca las clases privilegiadas pueden aspirar a una preponderancia tan antipolítica como en aquella nación [...]" (EL ESPECTADOR SEVILLANO 1809, p. 257). O en el periódico liberal El Tribuno del Pueblo Español se podrá leer: "Eran unos verdaderos Grandes y Prelados mientras unieron más sus intereses a los del Pueblo" (EL TRIBUNO DEL PUEBLO ESPAÑOL 1812, p. 68-70).

Es en realidad lo que se espera que hagan los nobles en los inicios del siglo XIX: que respeten la Constitución, la apoyen y luchen por defender los derechos de toda la nación y no solo sus antiguos privilegios. Es importante diferenciarlos de los nobles franceses de finales del siglo XVIII, cuyo pasado reprobable llevó al pueblo a unos extremos de violencia contra ellos.

Para algunos intelectuales incluso, la nobleza española habría sufrido en el pasado los mismos infortunios que el pueblo, al haber sido víctima ella misma del despotismo de los reyes (MARQUÉS DE SAN FELIPE 1811, p. 1275). La nobleza y el pueblo habrían tenido en el pasado, y así pues tendrían en el presente, los mismos intereses. 
Durante el Trienio liberal, liberales moderados y progresistas (denominados en este período como exaltados) seguirán interpretando el papel de la nobleza en el pasado en función del papel que deseaban que jugase en su presente. Por ello, se producirá en los discursos un desplazamiento de la oposición nobleza española versus nobleza europea en el pasado a una interpretación (también en el pasado) benéfica de la nobleza (por parte de los moderados) versus una interpretación más crítica (por parte de los progresistas). De nuevo, a través del uso de un solo concepto con doble y opuesta interpretación de su pasado histórico, se busca la definición ideológica de cada una de las tendencias del liberalismo y la acción en la defensa del modelo político propuesto. En este caso, habrá simetría en cuanto al uso de esta táctica en sus enfrentamientos políticos.

Desde una posición liberal moderada, que buscaba la integración de la nobleza en el nuevo edificio político en construcción, se insistirá en el carácter simbólico que con el pasar de los siglos habían ido adquiriendo los títulos nobiliarios. Así, desde las páginas del periódico El Universal, se afirmará que la nobleza, con el tiempo y su generalización, había perdido todo su significado y solo suponía "anteponer un monosílabo al nombre de bautismo" por lo que la igualdad política propuesta desde el articulado de la Constitución de 1812 no habría hecho más que reconocer una situación de facto (EL UNIVERSAL OBSERVADOR ESPAÑOL 1820, no 15).

El diputado Martínez de la Rosa también restará a la nobleza el carácter de amenaza al nuevo edificio político, pues considerará que no tenía ya ningún "odioso privilegio" y no se trataba de ninguna clase enemiga de la libertad (MARTÍNEZ DE LA ROSA 1821, p. 692). El diputado Garelli hablará incluso de la "domesticación" de la nobleza iniciada ya en el siglo XVI, nobleza que desde entonces habría estado más preocupada por su imagen que no por cuestiones políticas (GARELLI 1821, p. 743-744).

Los diputados menos moderados y los exaltados insistirán en cambio en el carácter brutal de la nobleza de época feudal, en sus intentos de restar poder a los reyes, lo cual explicaría el carácter ilegitimo de las posesiones nobiliarias adquiridas en el pasado y así pues justificaría el privarles de ellas en el presente (VADILLO 1821, p. 757). El diputado Martínez Marina remarcará esta interpretación negativa del papel de la nobleza feudal al afirmar que formó un estado dentro del estado y por tanto, que habría atentado contra la soberanía de la nación (en el pasado y así pues podía hacerlo en el presente)

Desde entonces la nobleza hereditaria, rica y poderosa, formó en medio de la nación, otro estado, un cuerpo numeroso, inquieto y turbulento, cuyas pretensiones ambiciosas y espíritu de insubordinación estaba en perpetuo choque, así contra la autoridad del príncipe, como con los derechos del pueblo. Los señores rara vez se unían para promover el bien común [...]. Trataban a los honrados vecinos como a esclavos (MARTÍNEZ MARINA 1821, p. 919).

Tras la muerte de Fernando VII y el ascenso al trono de su hija Isabel II (a través de su madre como Regente debido a su minoría de edad) se inicia la consolidación, 
no sin enormes dificultades, y la construcción definitiva del régimen liberal. La Constitución gaditana, motivo de tantos debates, pugnas y exaltaciones, empezará a perder protagonismo dado que el contexto político europeo, a estas alturas, había cambiado cobrando mayor relevancia el doctrinarismo francés así como las ideas de un gobierno moderado parlamentario inglés (VARELA SUANZES-CARPEGNA 2013). Asistiremos, a partir de ese momento, al intenso debate parlamentario en torno a la redacción del Estatuto Real de 1834, de la Constitución de 1837 y finalmente de la Constitución de 1845, que dará lugar a nuevas relecturas del pasado en particular en lo referente al papel de la nobleza en el pasado.

A pesar de haber sido aprobada ya en el Estatuto Real de 1834 la creación de una segunda cámara representativa, durante la redacción de la Constitución de 1837 se debatió intensamente en las Cortes la pertinencia de seguir teniendo una o dos cámaras representativas y en particular si el Senado debería de tener un carácter popular o no. Por lo general para los liberales progresistas esta segunda cámara debería ser de elección popular. Por ello estos diputados exaltarán el papel del pueblo en la historia (minusvalorando consecuentemente el papel de la nobleza) (HEROS 1837, p. 2600; ARGÜELLES 1837, p. 2658). El diputado González ante la posibilidad de un Senado aristocrático vitalicio y hereditario resaltará las características negativas de la nobleza a lo largo de la historia, en particular durante la guerra de las Comunidades (1520), hito en la pérdida de libertades: "¿Qué hicieron en las demás épocas los nobles? Que lo diga Villalar [...]. Ahogar aquel grito [del pueblo que clamaba por su independencia]". Para este diputado, los nobles fueron un azote y unos instrumentos de anarquía (GONZÁLEZ 1837, p. 2603). En el mismo sentido, el diputado Benegas afirmará en las Cortes:

Remontémonos a lo que eran en España los grandes antes de Carlos V. Eran entonces los únicos revolucionarios y reaccionarios de España, los que afligían a la Monarquía y a los pueblos, los que arrancaron para sí las gracias enriqueñas y los que se hicieron ricos-homes de pronto (BENEGAS 1837, p. 2629).

En cambio, los liberales moderados, partidarios por lo general de un Senado aristocrático, defenderán una interpretación del pasado donde nobles y pueblo aparecen hermanados y donde los nobles españoles fueron a lo largo de los siglos los verdaderos defensores de la libertad y de la civilización europea. Así el marqués de San Felices en un debate en el Senado afirmará:

El dueño de la cabaña y el señor del castillo, a las órdenes el uno del otro, juntos iban a reconquistar una patria y un altar, porque ambos eran españoles, y los señores del castillo no eran como en otras Naciones de una raza de origen extranjero y opresora; juntos dieron cima a la grande empresa de restablecer la España; y no solo la salvaron, sino que juntamente salvaron a la Europa entera, a la civilización occidental, pues a pesar de la victoria de Carlos Martel, una y cien veces hubieran atravesado los Pirineos los sarracenos, a no haberse encontrado con las incontrastables espadas españolas; espadas que eran nobles y plebeyas. Obedeciendo éstas, dirigiendo aquellas (MARQUÉS DE SAN FELICES 1844, p. 202). 
A lo largo de las páginas anteriores hemos podido observar como los conceptos asimétricos presentan una gran utilidad en los estudios sociales al encerrar en ellos una gran variedad de información: sirven como criterios de autoidentificación y de identificación del "Otro" así como de gestión del enfrentamiento entre grupos y reflejan los valores culturales de referencia e incluso contienen las representaciones sociales del pasado de cada grupo. Pero como he pretendido mostrar en este estudio, la aproximación a los contraconceptos debería realizarse desde una óptica amplia, que permita englobar las relaciones, en algunas de sus facetas, de simetría (dentro de la asimetría) así como centrar nuestra atención, más que en los términos específicos, en la carga valorativa que contienen, pues permite apreciar mejor la estructura asimétrica de la argumentación.

\section{Referencias bibliográficas}

ARGÜELLES, Diarios de Sesiones de las Cortes Generales y Extraordinarias (DSC). Madrid: imprenta de J. A. García, 1870-1874, 11 abril 1837, n. 166.

BARTLETT, Frederic C. Remembering. A study in experimental and social psychology. Cambridge: Cambridge University Press, 1932.

BAUMEISTER, Roy F.; HASTINGS, Stephen. Distortions of collective memory. How groups flatter and deceive themselves. En: PENNEBAKER, James W. ; PAÉZ, Dario; RIMÉ, Bernard (eds.). Collective memory of political events. Social Psychological Perspectives. Mahwa (N.J.): Lawrence Erlbaum, 1997.

BENEGAS, Diarios de Sesiones de las Cortes Generales y Extraordinarias (DSC). Madrid: imprenta de J. A. García, 1870-1874, 10 abril 1837, n. 165.

BOURDIEU, Pierre. Language and symbolic power. Cambridge: Polity Press, 1994.

van DIJK, Teun A. Ideología y discurso. Barcelona: Planeta, 2003.

EI Espectador Sevillano. Cuestión II: En el caso de la representación por estamentos, ¿deberá reunirse en un solo cuerpo, o dividirse en dos cámaras? (cont.), 5 diciembre 1809, n. 65.

El Tribuno del Pueblo Español. Legislación: Examen de los medios de hacer efectiva la responsabilidad del Poder Ejecutivo, 20 noviembre 1812, n. 6.

El Universal Observador Español. Constitución Española, 26 mayo 1820, n. 15.

FERES Jr, Joao. Building a typology of forms of misrecognition: beyond the Republican-Hegelian paradigm. Contemporary Political Theory, $n^{\circ} 5$, p. 259-277, 2006.

FERNÁNDEZ SEBASTIÁN, Javier. Tradiciones electivas. Cambio, continuidad y ruptura en historia intelectual, Almanack, n. 7, p. 5-26, 2014. 
De FINA, Anna; SCHIFFRIN, Deborah; BAMBERG, Michael (eds.). Discourse and identity. Cambridge: Cambridge University Press, 2006.

GARELLI, Diarios de Sesiones de las Cortes Generales y Extraordinarias (DSC). Madrid: imprenta de J. A. García, 1870-1874, 28 marzo 1821, n. 31.

GONZÁlEZ, Antonio. Diarios de Sesiones de las Cortes Generales y Extraordinarias (DSC). Madrid: imprenta de J. A. García, 1870-1874, 9 abril 1837, n. 164.

HARRÉ, Rom; van LANGENHOVE, Luk. The dynamics of social episodes. En: (eds.). Positioning theory: Moral contexts of intentional action. Oxford: Blackwell, 1999, p. 1-14.

HEROS, Diarios de Sesiones de las Cortes Generales y Extraordinarias (DSC). Madrid: imprenta de J. A. García, 1870-1874, 9 abril 1837, n. 164.

JUNGE, Kay; POSTOUTENKO, Kirill (eds.). Asymmetrical Concepts after Reinhart Koselleck. Historical Semantics and beyond. Bielefeld: Transcript Verlag, 2011.

. Self-concepts, Counter-concepts, asymmetrical counter-concepts. En: JUNGE, Kay; POSTOUTENKO, Kirill (eds.). Asymmetrical Concepts after Reinhart Koselleck. Historical Semantics and beyond. Bielefeld: Transcript Verlag, 2011, p. 9-49.

KOSELLECK, Reinhart. Begriffsgeschichten. Studien zur Semantik und

Pragmatik der politischen und sozialen Sprache. Frankfurt am Main:

Suhrkamp, 2006.

. Conceptos de enemigo. En: Historias de conceptos. Estudios sobre semántica y pragmática del lenguaje político y social. Madrid: Trotta, 2012, p. 189-197.

. "Progreso" y "Decadencia". Apéndice sobre la historia de dos conceptos. En: Historias de conceptos. Estudios sobre semántica y pragmática del lenguaje político y social. Madrid: Trotta, 2012, p. 95-112.

- Sobre la semántica histórico-política de los conceptos contrarios asimétricos. En: - Futuro pasado: para una semántica de los tiempos históricos. Barcelona: Paidós, 1993, p. 205-250

Vergangene Zukunft. Zur Semantik geschichtlicher Zeiten. Francfort: Verlag, 1979.

MARQUÉS DE SAN FELIPE. Diarios de Sesiones de las Cortes Generales y Extraordinarias (DSC). Madrid: imprenta de J. A. García, 1870-1874, 17 junio 1811, n. 258.

MARQUÉS DE SAN FELICES. Diarios de Sesiones de las Cortes Generales y Extraordinarias (DSC). Madrid: imprenta de J. A. García, 1870-1874, 30 diciembre 1844. DSC Senado, n. 23. 
MARTÍNEZ DE LA ROSA. Diarios de Sesiones de las Cortes Generales y Extraordinarias (DSC). Madrid: imprenta de J. A. García, 1870-1874, 25 marzo 1821, n. 28.

MARTÍNEZ MARINA. Diarios de Sesiones de las Cortes Generales y Extraordinarias (DSC). Madrid: imprenta de J. A. García, 1870-1874, 6 abril 1821, n. 40.

MOSCOVICI, Serge. The phenomenon of social representations. En: FARR, Robert M.; MOSCOVICI, Serge (eds.). Social representations. Cambridge: Cambridge University Press; Paris: Maison des Sciences de I'homme, 1984, p. 3-69.

POSTOUTENKO, Kirill. Asymmetrical Concepts and Political Asymmetries. A comparative glance at 20th Century Democracies and Totalitarianisms from a Discursive Standpoint. En: JUNGE, Kay; POSTOUTENKO, Kirill (eds.) Asymmetrical Concepts after Reinhart Koselleck. Historical Semantics and beyond. Bielefeld: Transcript Verlag, 2011, p. 81-113.

ROSA, Alberto; BELLELLI, Guglielmo; BAKHURST, David. Representaciones del pasado, cultura personal e identidad nacional. En: (eds.). Memoria colectiva e identidad nacional. Madrid: Biblioteca Nueva, 2000, p. 41-87. ; BLANCO, Florentino; TRAVIESO, David; HUERTAS, Juan A. Imaginado historias de España en el tiempo de unas elecciones generales. En: ROSA, Alberto; BELLELLI, Guglielmo; BAKHURST, David (Eds). Memoria colectiva e identidad nacional. Madrid: Biblioteca Nueva, 2000, p. 349-384.

ROUQUETTE, Michel Louis. Sur la connaissance des masses: essai de psychologie politique. Grenoble: Presses Universitaire de Grenoble, 1994.

SCHEGLOFF, Emanuel. Whose text? Whose context? Discourse and Society, v. 8, n. 2, p. 165-187, 1997.

SMITH, Anthony D. National identity. Londres: Penguin, 1991.

STROHSCHNEIDER, Peter: FremdeinderVormoderne. ÜberNegierbarkeitsverluste und Unbekanntheitsgewinne. En: Anja Becker (Hrsg.). Alterität als Leitkonzept für historisches Interpretieren. Reihe: Deutsche Literatur, Bd. 8, Berlin, Akademie-Verlag 2012, p. 388-416.

TODOROV, Tzvetan. El miedo a los bárbaros. Más allá del choque de civilizaciones. Barcelona: Círculo de lectores, 2008.

VADILLO, Diarios de Sesiones de las Cortes Generales y Extraordinarias (DSC). Madrid: imprenta de J. A. García, 1870-1874, 29 marzo 1821, n. 32.

VARELA SUANZES-CARPEGNA, Joaquín. La Monarquía doceañista (18101837). Madrid: Marcial Pons Historia, 2013.

WERTSCH, James V. Narrative tools of History and Identity. Culture and Psychology, v. 3, n. 1, p. 5-20, 1997. 